older Ss displayed positive contrast consequent to an increase in incentive size while younger individuals did not exhibit upward contrast effects.

In Experiments 3 and 4, while Ss could not be randomly assigned between age groups individuals were randomly allocated within each age group. That is to say, the young Ss may perhaps be a bit brighter than the older individuals. This is a difficulty that seems to arise in nearly all studies that compare different age groups.

It seems that positive and negative human incentive contrast effects found with adults do not occur with younger individuals. That is to say, age appears to be a controlling factor in the occurrence of incentive contrast effects in humans.

\section{REFERENCES}

BLACK, R. W. Shifts in magnitude of

reward and effects in instrumental and selective learning: A reinterpretation. Psychological Review, 1968, 75, 114-126.

ROBERTS, W. A. The effects of shifts in magnitude of reward on runway performance in immature and adult rats. Psychonomic Science, 1966, 5, 37-38.

VOGEL, J R , MIKULKA, P.J., \& SPEAR, N. E. Effects of interpolated extinction and level of training on the "depression effect." Journal of Experimental Psychology, 1966, 72, 51-60.

VOGEL, J. R., MIKULKA, P. J., \& SPEAR, N. E. Effects of shifts in sucrose and saccharine concentrations on licking behavior in the rat. Journal of Comparative \& Physiological Psychology, $1968,66,661-666$.

WEINSTEIN, L. Magnitude of incentive contrast as a function of amount of verbal reward change. Psychonomic Science, 1970, 21, 65-66.

WEINSTEIN, L., \& COLUCCI, V. M. Negative incentive contrast effects with verbal reinforcement. Psychonomic Science, $1970,18,318$.

\title{
Part-whole transfer of a taxonomic word list*
}

\author{
ROBERT L. HUDSON and JERRY L. DAVIS \\ Mississippi State University, State College, Miss. 39762
}

Three groups of Ss were given a part-whole transfer task where the words were members of taxonomic categories. Information regarding the taxonomic nature of the words was varied. The information-before (IB) group was given this information prior to the part list, the information-between (IBe) group received it prior to the whole list, and the no-information (NI) group was never given any information. Two control groups were included which were given taxonomic words in part-list learning which were not included in the whole list, i.e., category content was irrelevant. The information-between/irrelevant (IBe/I) group was given information regarding the whole list prior to the whole list, and the no-information/irrelevant (NI/I) group was given no information at all. $\bar{B}$ asically, the results indicated that both the IB and IBe groups exceeded the NI/I and NI groups in word recall. They did not, however, differ between themselves, except on Trial 1 of the whole list when only "old" words recalled were considered. Implications of these results were discussed.

In studies of free recall using categorizable word lists, several investigators have demonstrated that many variables will affect the extent or organization, where organization is defined as consecutive recall of words from the same category, i.e., clustering. One thing conspicuous about these studies, however, is that increased recall is not necessarily concomitant with increased organization (Cofer, 1967). In many studies, there is a paradox in that there is a tendency for Ss who cluster more to recall more words; yet, "artificially" increasing the tendency to organize into E-defined units does

*This research was partially supported by institutional funds granted to Mississippi State University by the National Science Foundation. Requests for reprints should be sent to Robert L. Hudson, Drawer PF, State College, Miss. 39762 . not increase the actual number of words recalled.

Hudson \& Davis (1970) attempted to demonstrate positive transfer of both clustering and number of words recalled in a part-whole transfer paradigm using words from the Underwood \& Richardson (1956) norms. They hypothesized that when the whole list consists of the part list plus additional words from each category, the part-list organization would be effective for organizing the whole list. This should be true for a group [information-before (IB)] told prior to part-list learning that the words can be categorized along with the category names. The nature of the word lists is such, however, that a group never given this information [no-information (NI) group] should essentially be equivalent to a group learning unrelated words. Hence, in whole-list learning, the IB group should exceed the NI group in both clustering and words recalled. Hudson \& Davis (1970) also included a third group [information-between (IBe)] which was given the category names prior to whole-list learning only. Any difference between this group and the NI group should reflect effects of information per se, and any difference between the IB group and IBe group should reflect effects due to either differences in transfer of organization or, possibly, differences in retention. The trend of the results of their data was as predicted, but was generally nonsignificant.

The study which follows was a modification of the Hudson \& Davis (1970) design in an attempt to demonstrate that in free recall studies of categorizable word lists, increased recall will be a concomitant of increased E-defined organization when such organization is more efficient than other systems. The present study utilized taxonomic word lists with four words from each of 10 categories. In addition to the three groups previously mentioned (IB, IBe, and NI), two other groups were added. The no-information/irrelevant (NI/I) and information-between/irrelevant ( $\mathrm{IBe} / \mathrm{I}$ ) groups were treated like the NI and IBe groups, respectively, except that the Task 1 words learned by these groups were not present in the Task 2 list and shared no categories in common with the Task 2 list. The NI/I group, then, would be the appropriate baseline group from which to judge negative or positive transfer in the other groups. In addition, the NI and NI/I groups should provide a replication of Tulving's (1966) original part-to-whole transfer study as the NI group would be expected to exceed the NI/I group on the first trial or two of whole-list learning, but the NI group should be inferior over the remaining trials because, presumably, the organization this group imposed on part-list learning would generally not be appropriate for whole-list learning.

Thus, the hypothesis of the study was that on at least the first trial or two, the IB group would exceed the other groups, but on later trials would not exceed the IBe group. We expected that the $\mathrm{IBe} / \mathrm{I}$ group would have an initial depression compared to the IB and IBe groups but would later catch up. In accordance with Tulving's previous findings, we expected the NI group to exceed the NI/I group on the first trial or two and to be depressed from that point on.

\section{SUBJECTS}

The Ss were 75 male and female introductory psychology students who served in order to fulfill a course requirement.

MATERIALS

Forty words were chosen from the 
extended Connecticut Category norms of Battig \& Montague (1969), with four words from each of 10 categories. These 40 words constituted the whole list for all groups. To form the part lists, two words were chosen at random from each category. The remaining words constituted a second equivalent part list. Half the Ss from each of the IB, IBe, and NI groups received one part list, and the other half received the other part list.

The irrelevant part list was composed of two words from each of 10 categories from the Battig \& Montague (1969) norms. Neither the categories nor words were the same as the relevant part lists. All Ss in the $\mathrm{IBe} / \mathrm{I}$ and NI/I groups received this list as their part list.

For the three part lists and the whole list, the order of the words on the memory drum tape was determined at random. There were five random orders of each part list and six random orders of the whole list. Two Stowe memory drums were used to present the words.

\section{PROCEDURE}

The five levels of the independent variable were determined by the combination of part list learned and point of instruction regarding the categorical nature of the words forming the five groups already named.

The Ss were treated individually and were assigned at random to the five conditions in blocks of five. There were $15 \mathrm{Ss}$ in each of the five groups. Each $\mathrm{S}$ was assigned randomly to one of five starting positions on his part list and to one of six starting positions on the whole list. Each $\mathrm{S}$ received five presentation-recall trials on the part list, with the words being presented at a 2 -sec rate. One minute was allowed for recall on each trial. The $S$ was then read appropriate instructions for the whole list and given six presentation-recall trials on the whole list at a 2 -sec rate. Two and one-half minutes were allowed for each recall of the whole list.

RESULTS AND DISCUSSION

The mean total number of words recalled (with SDs in parentheses) over the five trials of the part list were 69.1 (13.9), 68.3 (10.3), 60.6 (7.5), 61.1 (12.7), and $67.6(11.0)$ for the IB, IBe, NI, NI/I, and IB/I groups, respectively. A completely randomized analysis of variance indicated an $\mathrm{F}(4,70)=1.88$, $\mathrm{p}>.10$. The mean clustering indexes (using the ratio of repetition) for the fifth trial of the part list were (with SDs in parentheses) .64 (.32), .49 $(.30), .34(.35), .42(.37)$, and .48 (.32) for the IB, IBe, NI, NI/I, and $\mathrm{IBe} / \mathrm{I}$ groups, respectively. A completely randomized analysis of variance on the clustering indexes of

Table 1

Mean Number of Total Words Recalled, Clustering Index (CI), New Words Recalled, and Old Words Recalled for the Six Trials of the Whole List

\begin{tabular}{|c|c|c|c|c|c|c|c|}
\hline \multirow[b]{2}{*}{ Measure } & \multirow[b]{2}{*}{ Condition } & \multicolumn{6}{|c|}{ Trial } \\
\hline & & 1 & 2 & 3 & 4 & 5 & 6 \\
\hline Total Words & $\begin{array}{l}\text { IB } \\
\text { IBe } \\
\text { NI } \\
\text { IBe-I } \\
\text { NI-I }\end{array}$ & $\begin{array}{l}23.9 \\
20.0 \\
18.1 \\
17.5 \\
13.9\end{array}$ & $\begin{array}{l}29.1 \\
28.7 \\
22.2 \\
24.8 \\
22.1\end{array}$ & $\begin{array}{l}31.3 \\
31.1 \\
23.5 \\
27.3 \\
26.1\end{array}$ & $\begin{array}{l}32.7 \\
32.6 \\
25.4 \\
28.5 \\
27.7\end{array}$ & $\begin{array}{l}32.1 \\
34.5 \\
26.0 \\
30.5 \\
29.5\end{array}$ & $\begin{array}{l}33.6 \\
36.0 \\
26.4 \\
33.0 \\
29.9\end{array}$ \\
\hline $\mathrm{CI}$ & $\begin{array}{l}\text { IB } \\
\text { IBe } \\
\text { NI } \\
\text { IBe-I } \\
\text { NI-I }\end{array}$ & $\begin{array}{l}5.75 \\
5.64 \\
2.21 \\
5.65 \\
3.06\end{array}$ & $\begin{array}{l}\mathbf{8 . 7 2} \\
\mathbf{8 . 0 0} \\
\mathbf{3 . 7 0} \\
\mathbf{7 . 5 0} \\
\mathbf{5 . 6 7}\end{array}$ & $\begin{array}{r}10.27 \\
10.19 \\
4.16 \\
8.70 \\
7.40\end{array}$ & $\begin{array}{r}10.51 \\
10.62 \\
3.95 \\
9.01 \\
8.08\end{array}$ & $\begin{array}{r}20.92 \\
11.19 \\
4.99 \\
9.80 \\
8.74\end{array}$ & $\begin{array}{r}10.69 \\
11.86 \\
5.38 \\
10.94 \\
8.15\end{array}$ \\
\hline New Words & $\begin{array}{l}\text { IB } \\
\text { IBe } \\
\text { NI }\end{array}$ & $\begin{array}{l}9.3 \\
8.9 \\
7.3\end{array}$ & $\begin{array}{l}13.7 \\
13.9 \\
10.3\end{array}$ & $\begin{array}{l}15.4 \\
15.9 \\
11.0\end{array}$ & $\begin{array}{l}16.3 \\
17.1 \\
12.4\end{array}$ & $\begin{array}{l}16.5 \\
17.5 \\
13.1\end{array}$ & $\begin{array}{l}17.2 \\
18.4 \\
13.1\end{array}$ \\
\hline Old Words & $\begin{array}{l}\text { IB } \\
\text { IBe } \\
\text { NI }\end{array}$ & $\begin{array}{l}14.7 \\
11.1 \\
10.8\end{array}$ & $\begin{array}{l}15.4 \\
14.7 \\
11.8\end{array}$ & $\begin{array}{l}15.9 \\
15.3 \\
12.5\end{array}$ & $\begin{array}{l}16.4 \\
15.5 \\
12.9\end{array}$ & $\begin{array}{l}15.5 \\
17.0 \\
12.9\end{array}$ & $\begin{array}{l}16.4 \\
17.6 \\
13.3\end{array}$ \\
\hline
\end{tabular}

the fifth trial revealed an $\mathrm{F}(4,70)=1.45, \mathrm{p}>.10$.

Table 1 indicates the mean total number of words recalled and mean clustering indexes for the five groups at each of the six trials of whole-list learning. Table 1 also indicates the mean number of "old" words recalled and mean number of "new" words recalled for the $\mathrm{IB}, \mathrm{IBe}$, and NI groups on each of the six trials of whole-list learning.

The first thing to note is the performance of the NI/I and NI groups. The NI group exceeds the NI/I group on Trial 1, but after Trial 2, the NI/I group rapidly exceeds the NI group. Thus, the performance of these two groups is perfectly analogous to the performance of Tulving's (1966) control and experimental groups. This would indicate that in the absence of information regarding the categorical nature of the lists the Ss treat these words in the same manner as they would "unrelated" words. Thus the appropriate baseline group for the assessment of positive transfer is the NI/I group.

A 5 by 6 split-plot analysis of variance of the clustering indexes (Dunn, 1969) of Task 2 revealed the following: conditions, $F(4,70)=4.36$, $\mathrm{p}<.01 ;$ Conditions by Trials interaction, $F(20,350)=1.26, p>.05$; trials, $F=54.78, \mathrm{p}<.01$. Subsequent analysis using Tukey's HSD test revealed that the $I B, I B e$, and $I B e / I$ groups significantly exceeded the NI group. They did not, however, significantly exceed the NI/I group. Of major interest is the fact that the IB and IBe groups did not differ at any point while they both exceeded the NI group as a main effect. Thus, there is little direct evidence for the transfer of any E-defined organization.

A 5 by 6 split-plot analysis of variance for the total number of words recalled revealed the following: conditions, $\mathrm{F}(4,70)=3.99, \mathrm{p}<.01$; Conditions by Trials interaction, $\mathrm{F}(20,350)=2.73, \quad \mathrm{p}<.01$; trials, $\mathrm{F}(5,350)=166.04, \quad \mathrm{p}<.01$. Subsequent comparisons of simple main effects and Tukey's HSD test indicated, generally, that the IB and IBe groups exceeded both the NI/I and NI groups. The IB group significantly exceeded the IBe/I group on Trial 1 . Throughout the middle trials, the difference between the IBe and IB groups and the IBe/I group was just short of significance. This would indicate that information does have an effect in a transfer situation, although the effect is not due to transfer of organization, per se, because the IB and IBe groups do not differ. This may result from several things, one being that possibly the IB and IBe groups did not differ on part list organization. Since they do exceed the other groups, however, this would indicate that the necessary conditions are prior exposure to a part of the words and information at some point prior to Task 2. Neither prior exposure to a part of the words alone (NI group) or information prior to Task 2 alone (IBe/I group) is sufficient, and information prior to Task 1 (IB group) is not necessary. Therefore, while information does not lead to more words recalled on a first task, the combination of prior exposure to a list of words and information will lead to more words recalled on a subsequent learning task incorporating the old words as well as new words from the same categories. It should be noted that the IB group does exceed the IBe group on Trial 1 of Task 2, although not significantly. In an effort to further analyze the possibility of significant transfer effects of the IB group over the IBe group, the data for the IB, IBe, and NI groups on Task 2 
were divided into old words and new words. These data are presented in Table 1 . A 5 by 6 split-plot analysis of variance for the number of new words recalled revealed the following: conditions, $\mathrm{F}(2,42)=6.94, \mathrm{p}<.01$; Conditions by Trials interaction, $F(10,210)=1.94 ; \quad p<.05 ;$ trials, $F(5,210)=104.17, \quad p<.01$. The nature of the significant interaction was no difference between the three groups on Trial 1 , and the IB and IBe groups both significantly exceeded the NI group from Trial 2 through Trial 6 , but the $I B$ and $I B e$ groups never differed.

A 5 by 6 split-plot analysis of variance for the number of old words recalled was also carried out, with the following results: conditions, $\mathrm{F}(4,70)=5.18, \mathrm{p}<.01 ;$ Conditions by Trials interaction, $\mathbf{F}(10,210)=3.31$, $\mathrm{p}<.01$; trials, $\mathrm{F}=16.12, \mathrm{p}<.01$. The significant interaction resulted from the fact that the IB group significantly exceeded both the IBe and NI groups on Trial 1 and the IB and IBe groups both significantly exceeded the NI group on Trials 2 through 6 .

Thus the IB group did not show greater positive transfer than the IBe group on the first trial of the transfer task, since the only difference is in retention of the old words. One could hypothesize that this retention difference was due to the greater, although insignificantly so, clustering of the IBe group when compared with the IBe group on Task 1. It would seem that if a greater organizational difference could be attained on Task 1 , then transfer to Task 2 would follow. It would appear necessary, however, that one carefully separate retention differences from transfer differences in part-whole studies. Finally, it could be argued that this retention difference does provide indirect support for differences in the transfer of organization, i.e., the fact that the IB group exceeds the IBe group in number of old words recalled is because the superior organization of the IB group in part learning is carried over the whole list.

REFERENCES

BAtTig, W. F., \& MONTAGUE, W. E. Category norms for verbal items in 56 categories: A replication and extension of the Connecticut Category norms. Journal of Experimental Psychology, 1969, 80(3, pt. 2),

COFER, D. Does conceptual organization influence the amount retained in immediate free recall? In $B$. Kleinmuntz (Ed.), Concepts and the structure of memory. New York: Wiley, 1967. Pp. 181-214.

DUNN, J. E. A compound multiple runs distribution. Journal of the American Statistical Association, $1969,64$. $1415 \cdot 1423$

HUDSON, R. L., \& DAVIS, J. L. Part-whole transfer of a categorizable word list. Psychonomic Science. 1970, 21, 331-332.

TULVING, E. Subjective organization and effects of repetition in multi-trial free-recall learning. Journal of Verbal Learning \& Verbal Behavior, 1966, 5, 193-197.

UNDER WOOD, B. J., \& RICHARDSON, J. Some verbal materials for the study of concept formation. Psychological Bulletin, 1956, 53, 84-95. 